\title{
Coupling of Vinylic Tellurides with Alkynes Catalyzed by Palladium Dichloride: Evaluation of Synthetic and Mechanistic Details
}

\author{
Cristiano Raminelli, ${ }^{\dagger}$ Martin H. G. Prechtl, ${ }^{\dagger}$ Leonardo S. Santos, ${ }^{\ddagger}$ \\ Marcos N. E berlin, ${ }^{\ddagger}$ and J oão V. Comasseto*,t \\ Instituto de Química, Universidade de São Paulo, Av. Prof. Lineu Prestes, 748, \\ CEP 05508-900, São Paulo, SP, Brazil, and Instituto de Química, Universidade Estadual de \\ Campinas, CEP 13083-970, Campinas, SP, Brazil
}

Received March 17, 2004

\begin{abstract}
Under palladium dichloride catalysis, vinylic tellurides couple efficiently with alkynes with retention of the double-bond geometry. Herein we show that the amount of the $\mathrm{PdCl}_{2}$ catalyst can be reduced from $40 \mathrm{~mol} \%$ to $10 \mathrm{~mol} \%$ by using copper(II) chloride as an oxidizing agent. Under these conditions, an inert atmosphere is no longer required and the reaction occurs quite efficiently in the presence of air, leading to the enynes in $40-82 \%$ isolated yields. Mass and tandem mass spectrometric experiments using electrospray ionization were performed, and $\mathrm{Pd}$-Te cationic intermediates were, for the first time, intercepted and transferred to the gas phase for structural characterization. An expanded catalytic cycle for this important method for enyne synthesis is proposed.
\end{abstract}

\section{Introduction}

In the last two decades, the ability of organotellurium compounds to promote the stereocontrolled formation of carbon-carbon bonds has been widely explored. ${ }^{1} \mathrm{M}$ ost of the methods devel oped for this purpose are stoichiometric processes and involve the transformation of the organotellurium compound into a reactive organometallic, mainly organolithium ${ }^{1-5}$ and organocopper ${ }^{1,6-8}$ reagents. In the context of green chemistry, the development of catalytic methods to promote carbon-carbon bond formation is highly recommended; 9 hence, our group has been exploring the use of catalytic processes in organic tellurium chemistry. Several years ago Uemura published his pioneering report on the carbodetelluration of organotellurium compounds catalyzed by a palladium(II) salt. ${ }^{10}$ In this and subsequent works ${ }^{11-13}$ Uemura emphasized the influence of the substrate structure and the reaction medium in the

* To whom correspondence should be addressed. Tel: +55 11 30912176. Fax: +55 11 38155579. E-mail: jvcomass@iq.usp.br.

† Universidade de São Paulo.

₹ Universidade Estadual de Campinas.

(1) Comasseto, J . V.; Barrientos-Astigarraga, R. E. Aldrichim. Acta 2000, 33(2), 66

(2) Kauffmann, T. Angew. Chem., Int. Ed. Engl. 1982, 21, 410.

(3) Hiiro, T.; Kambe, N.; Ogawa, A.; Miyoshi, N.; Murai, S.; Sonada, N. Angew. Chem., Int. Ed. Engl. 1987, 26, 1187.

(4) Barros, S. M.; Comasseto, J . V.; Berriel, 」. Tetrahedron Lett. 1989, 30, 7353 .

(5) Dabdoub, M. J .; Dabdoub. V. M. B.; Comasseto, J . V. Tetrahedron Lett. 1992, 33, 2261.

(6) Comasseto, J . V.; Berriel, J . Synth. Commun. 1990, 20, 1681

(7) Tucci, F. C.; Chieffi, A.; Comasseto, J. V. J . Org. Chem. 1996, 61, 4975.

(8) de Araújo, M. A.; Comasseto, J. V. Synlett 1995, 1145.

(9) Anastas, P. T.; Kirchhoff, M. M. Acc. Chem. Res. 2002, 35, 686

(10) Uemura, S.; Wakasugi, M.; Okano, M. J . Organomet. Chem. 1980, 194(3), 277.

(11) Uemura, S.; Takahashi, H.; Ohe, K.J . Organomet. Chem. 1992, 423, C9-C12.

(12) Nishibayashi, Y.; Cho, C. S.; Uemura, S. J . Organomet. Chem. 1996, 507, 197. course of the catalyzed transformations. In 1999, we reported the alkynylation reaction of butyl vinyl tellurides (1) promoted by $\mathrm{PdCl}_{2} / \mathrm{Cul}$ (eq 1). ${ }^{14}$ Shortly

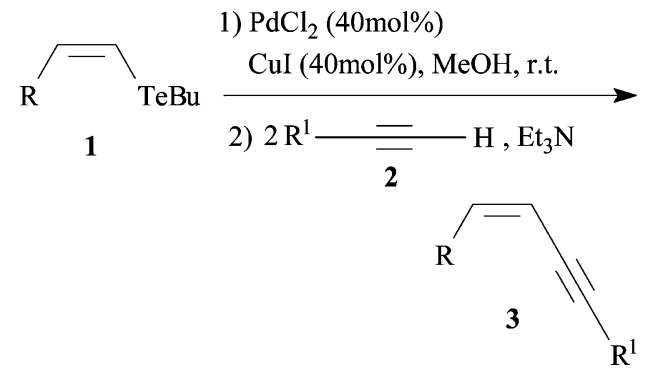

thereafter Dabdoub and Marino reported the coupling of vinylic tellurides with alkynylzinc catalyzed by palIadium. ${ }^{15}$ More recently, Zeni et al. reported several couplings of alkynes with vinylic and aromatic tellurides promoted by palladium dichloride. ${ }^{16-24}$ The Pd-catalyzed

(13) Nishibayashi, Y.; Cho, C. S.; Ohe, K.; Uemura, S. J . Organomet. Chem. 1996, 526, 335.

(14) Zeni, C.; Comasseto, J . V. Tetrahedron Lett. 1999, 40, 4619

(15) Dabdoub, M. J .; Dabdoub. V. B.; Marino, J . P. Tetrahedron Lett. 2000, 41, 437

(16) Zeni, G.; Menezes, P. H.; Moro, A. V.; Braga, A. L.; Silveira, C. C. Synlett 2001, 9, 1473.

(17) Zeni, G.; Nogueira, C. W.; Panatieri, R. B.; Silva, D. O.; Menezes, P. H.; Braga, A. L.; Silveira, C. C.; Stefani, H. A.; Rocha, J. B. T. Tetrahedron Lett. 2001, 42, 7921.

(18) Braga, A. L.; de Andrade, L. H.; Silveira, C. C.; Moro, A. V.; Zeni, G. Tetrahedron Lett. 2001, 42, 8563.

(19) Zeni, G.; Lüdtke, D. S.; Nogueira, C. W.; Panatieri, R. B.; Braga A. L.; Silveira, C. C.; Stefani, H. A.; Rocha, J . B. T. Tetrahedron Lett. 2001, 42, 8927.

(20) Zeni, G.; Perin, G.; Cella, R.; J acob, R. G.; Braga, A. L.; Silveira, C. C.; Stefani, H. A. Synlett 2002, 6, 975.

(21) Braga, A. L.; Vargas, F.; Zeni, G.; Silveira, C. C.; de Andrade, L. H. Tetrahedron Lett. 2002, 43, 4399.

(22) Zeni, G.; Nogueira, C. W.; Silva, D. O.; Menezes, P. H.; Braga A. L.; Stefani, H. A.; Rocha, J . B. T. Tetrahedron Lett. 2003, 44, 685.

(23) Zeni, G.; Nogueira, C. W.; Silva, D. O.; Menezes, P. H.; Braga,

A. L.; Stefani, H. A.; Rocha, J . B. T. Tetrahedron Lett. 2003, 44, 1387. 


\section{Chart 1}
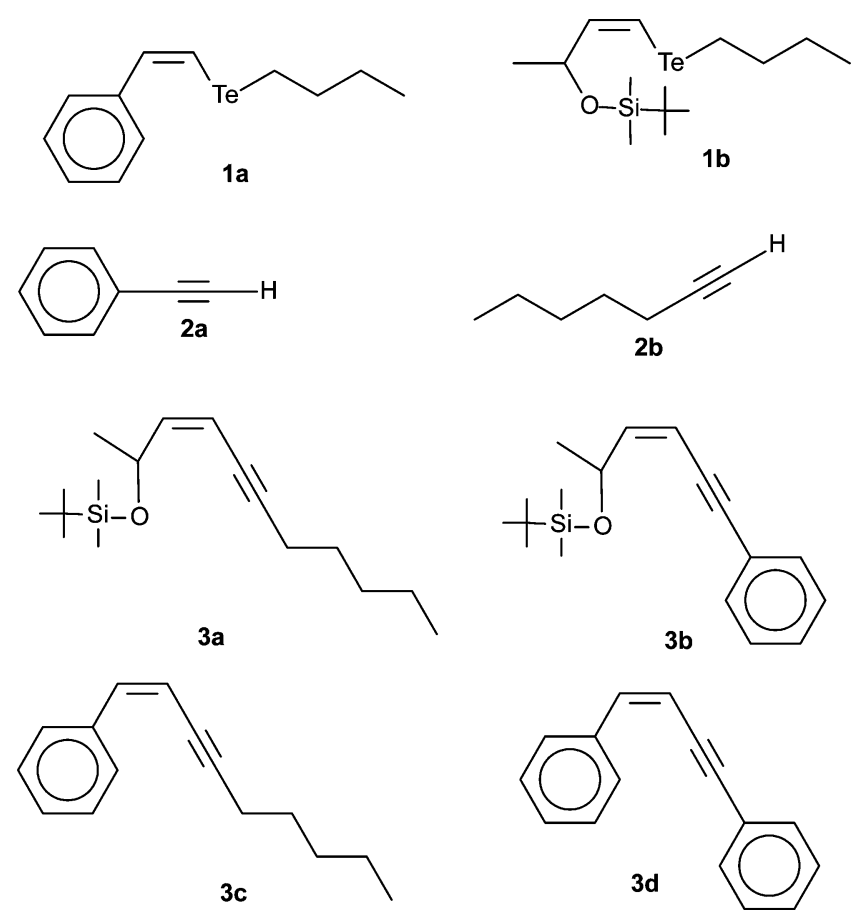

alkynylation has been recently reviewed and is nowadays one of the most important methods for the synthesis of alkynes. ${ }^{25}$ The reaction developed in our laboratory (eq 1) uses $40 \mathrm{~mol} \%$ of both $\mathrm{PdCl}_{2}$ and Cul . Owing to its high cost, it is mandatory to downsize the amount of palladium dichloride necessary to promote the coupling reaction in good yields if one plans to use this reaction in cost-effective preparative organic chemistry. Many catalytic reactions are al so highly sensitive to small changes in experimental conditions; therefore, the general reaction procedure must be car efully established to allow reproducibility. Toward this end, a systematic evaluation of the reaction variables (eq 1 ) must be done to shed light on the limiting factors of this interesting coupling reaction. To perform such an evaluation, we have chosen two butyl vinyl tellurides, one aromatic (1) and one al i phatic presenting some degree of steric hindrance at $\mathrm{C}_{3}(\mathbf{1 b})$, and phenylacetylene (2a) and 1-heptyne (2b) as the al kynes. The products formed were the enynes $\mathbf{3 a}-\mathbf{d}$ (Chart 1). The solvent, the base, and the temperature remained the same, and the amounts of $\mathrm{PdCl}_{2}$ and Cul were varied as described in Table 1 (entries $1-5$ ). The reaction was also performed in the absence of Cul (Table 1, entries 6-8). Finally, several oxidizing agents or additives other than Cul were tested. In this paper we report the results of this systematic study with full experimental details and mechanistic reevaluation.

\section{Results and Discussion}

We initiated this study by performing the coupling reaction under anhydrous conditions and under a nitrogen atmosphere. The reaction of the vinylic telluride $\mathbf{1}$ with the alkyne $\mathbf{2}$ in the presence of $\mathrm{PdCl}_{2}$ and

(24) Zeni, G.; Nogueira, C. W.; Pena, J . M.; Pilissão, C.; Menezes, P. H.; Braga, A. L.; Rocha, J. B. T. Synlett 2003, 4, 579.

(25) Zeni, G.; Braga, A. L.; Stefani, H. A. Acc. Chem. Res. 2003, 36(10), 731
Table 1. Influence of the Amount of $\mathrm{PdCl}_{2}$ and $\mathrm{Cul}$ in the Coupling Reaction of Vinylic Tellurides (1) with Terminal Alkynes (2)

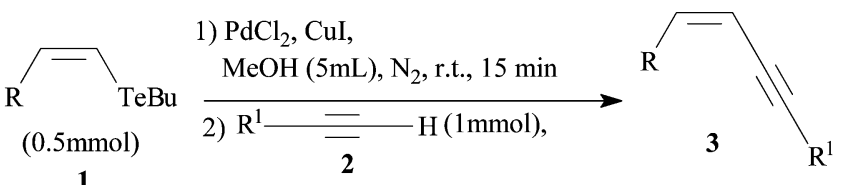

$$
\begin{aligned}
& 1 \quad \mathrm{Et}_{3} \mathrm{~N}(2 \mathrm{mmol}), \mathrm{N}_{2} \text {, r.t., 6-12 h } \\
& \text { 3a: } \mathrm{R}=\overbrace{\mathrm{OSiMe}_{2}(\mathrm{t}-\mathrm{Bu})}^{\xi} ; \mathrm{R}^{1}=\mathrm{C}_{5} \mathrm{H}_{11} \\
& \text { 3b: } \mathrm{R}=\overbrace{\mathrm{OSiMe}_{2}(\mathrm{t}-\mathrm{Bu})}^{\xi} ; \mathrm{R}^{1}=\mathrm{Ph}
\end{aligned}
$$

\begin{tabular}{|c|c|c|c|c|c|c|}
\hline \multirow[b]{2}{*}{ entry } & \multicolumn{2}{|c|}{ amt (mol \%) } & \multicolumn{4}{|c|}{ conversnc (\%) } \\
\hline & $\mathrm{PdCl}_{2}$ & Cul & $3 a^{d}$ & $3 \mathbf{b}^{d}$ & $3 c^{e}$ & $3 d^{e}$ \\
\hline 1 & 20 & 20 & 19 & 30 & 45 & 26 \\
\hline 2 & 40 & 40 & 49 & 54 & 80 & 75 \\
\hline 3 & 60 & 60 & 60 & 94 & $>99$ & 97 \\
\hline 4 & 80 & 80 & 95 & 98 & $>99$ & 99 \\
\hline $5^{a}$ & 100 & 100 & $>99$ & $>99$ & $>99^{f}$ & 98 \\
\hline $6^{b}$ & 20 & & 18 & 24 & 22 & 27 \\
\hline $7^{\mathrm{b}}$ & 40 & & 56 & 58 & 54 & 62 \\
\hline $8^{b}$ & 100 & & $>99$ & 98 & $>999$ & $>99$ \\
\hline
\end{tabular}

3c: $\mathrm{R}=\mathrm{Ph} ; \mathrm{R}^{1}=\mathrm{C}_{5} \mathrm{H}_{11}$

3d: $\mathrm{R}=\mathrm{Ph} ; \mathrm{R}^{1}=\mathrm{Ph}$

a This reaction was carried out using $1 \mathrm{mmol}$ of the vinylic telluride $\mathbf{1}, 2 \mathrm{mmol}$ of the alkyne $2,4 \mathrm{mmol}$ of $\mathrm{Et}_{3} \mathrm{~N}$, and $10 \mathrm{~mL}$ of $\mathrm{MeOH}$. Isolated yields: 89\% (3a), 92\% (3b), 93\% (3c), and 93\% (3d). ${ }^{b}$ The reaction was performed in the absence of Cul. ${ }^{c} \mathrm{De}-$ termined by gas chromatography relative to the starting materials

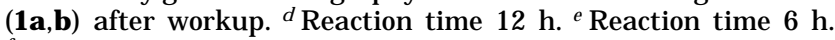
${ }^{f}$ Compound $\mathbf{3 c}$ was not obtained when the reaction was carried out without $\mathrm{PdCl}_{2} .{ }^{9}$ Carried out using $1 \mathrm{mmol}$ of $\mathbf{1 a}, 2 \mathrm{mmol}$ of $\mathbf{2 b}, 4 \mathrm{mmol}$ of $\mathrm{Et}_{3} \mathrm{~N}$, and $10 \mathrm{~mL}$ of $\mathrm{MeOH}$. Isolated yield: $75 \%$.

Cul , leading to the enyne 3, was performed as described in Table 1 . The best results were obtained when stoichiometric amounts of $\mathrm{PdCl}_{2}$ and Cul were used (entry 5). Under these conditions the isolated yields were in the range of $90 \%$ for all compounds prepared. By using 80 and $60 \mathrm{~mol} \%$ of $\mathrm{PdCl}_{2}$ and Cul, the conversion was still high, except for compound $\mathbf{3 a}$, indicating the lower reactivity of the aliphatic alkyne $\mathbf{2 b}$ relative to $\mathbf{2 a}$. When the amount of $\mathrm{PdCl}_{2}$ and $\mathrm{Cul}$ was reduced to $40 \mathrm{~mol} \%$, the conversions were still acceptable for $\mathbf{3 c}$ and $\mathbf{3 d}$, but they dropped considerably for $\mathbf{3 a}$ and $\mathbf{3 b}$ (entry 2). At $20 \mathrm{~mol} \%$ of the catalysts the conversions are low in all cases (entry 1). In all experiments the homocoupling product alkyne-alkyne was observed as a byproduct, in agreement with other reports in which similar conditions were employed. ${ }^{26}$ Next, we examined the influence of Cul by performing the reaction with no addition of this salt. The results (Table 1, entries 6-8) showed that Cul has little effect in the conversion of $\mathbf{1}$ into $\mathbf{3}$. As in the reaction in the presence of Cul, the homocoupling alkyne-alkyne product was also formed, as well as other nonidentified byproducts. Searching for better conditions to perform the coupling reaction, we tested several oxidizing agents or additives as attempts to reduce the amount of $\mathrm{PdCl}_{2}$. The same general procedure described in Table 1 was used, and the results are summarized in Table 2 . The

(26) Negishi, E.; Anastasia, L. Chem. Rev. 2003, 103, 1979. 
Table 2. Influence of the Oxidizing Agent or Additive in the Palladium-Catalyzed Coupling Reaction of the Vinylic Telluride la with Alkyne $2 b$

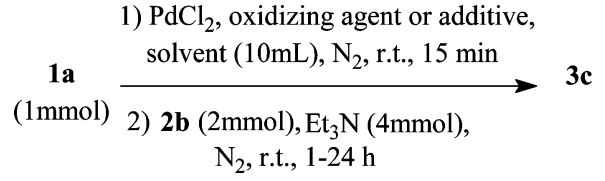

\begin{tabular}{cclccc}
\hline entry & $\begin{array}{c}\text { amt of } \mathrm{PdCl}_{2} \\
(\mathrm{~mol} \mathrm{\% )}\end{array}$ & $\begin{array}{c}\text { oxidizing agent } \\
\text { or additivec }\end{array}$ & \multicolumn{1}{c}{ solvent } & $\begin{array}{c}\text { time conversn } \\
(\mathrm{h})^{\mathrm{g}}\end{array}$ & $\begin{array}{c}\text { con } \\
(\%\end{array}$ \\
\hline 1 & 10 & $\mathrm{~K}_{2} \mathrm{~S}_{2} \mathrm{O}_{8}{ }^{\mathrm{d}}$ & $\mathrm{MeOH}$ & $1^{\mathrm{h}}$ & 80 \\
2 & 10 & $\mathrm{CH}_{3} \mathrm{COOAg}^{\mathrm{e}}$ & $\mathrm{MeOH}$ & $3^{\mathrm{h}}$ & 12 \\
3 & 10 & $\mathrm{FeCl}_{3}$ & $\mathrm{MeOH}$ & $1^{\mathrm{h}}$ & 25 \\
4 & 10 & $\mathrm{Cul}^{\mathrm{h}}$ & $\mathrm{MeOH}$ & $1^{\mathrm{h}}$ & 24 \\
5 & 10 & $\mathrm{ZnCl}_{2}$ & $\mathrm{MeOH}$ & $1^{\mathrm{h}}$ & 11 \\
6 & 10 & $\mathrm{CuCl}_{2}$ & $\mathrm{MeOH}$ & $24^{\mathrm{i}}$ & $91^{\mathrm{k}}$ \\
$7 \mathrm{a}$ & 10 & $\mathrm{CuCl}_{2}$ & $\mathrm{MeOH}$ & $24^{\mathrm{i}}$ & $94^{\mathrm{k}}$ \\
8 & 20 & $\mathrm{CuCl}_{2}$ & $\mathrm{MeOH}$ & $24^{\mathrm{i}}$ & 90 \\
9 & 10 & $\mathrm{CuCl}_{2}$ & $\mathrm{DMF} / \mathrm{HF}^{\mathrm{f}}$ & $24^{\mathrm{i}}$ & 71 \\
$10^{\mathrm{b}}$ & 10 & $\mathrm{CuCl}_{2}$ & $\mathrm{MeOH}$ & $24^{\mathrm{i}}$ & 93
\end{tabular}

a Carried out with $4 \mathrm{mmol}$ of $\mathrm{CuCl}_{2}$. ${ }^{\text {b }}$ Carried out under dry conditions in the absence of an inert atmosphere, without stirring for $15 \mathrm{~min}$ after the addition of the reagents and using $1.1 \mathrm{mmol}$ of 1-heptyne. I solated yield: $63 \%$. ' The amount used was $2 \mathrm{mmol}$ in all cases. ${ }^{\mathrm{d}}$ Added after the $\mathrm{PdCl}_{2}$ and not flame-dried under a stream of deoxygenated and dry nitrogen. ${ }^{e}$ Added after the $\mathrm{PdCl}_{2}$, not flame-dried under a stream of deoxygenated and dry nitrogen, and carried out in the absence of light. ${ }^{\mathrm{f}} \mathrm{DMF} / \mathrm{THF}=6 \mathrm{~mL} / 6 \mathrm{~mL}$. 9 Determined by GC. ${ }^{\mathrm{h}}$ After this time conversions did not increase. i The reaction was stopped after stirring for the reported time. j Determined by GC. ${ }^{k}$ Average value of two runs.

Table 3. Yields of the Enynes $3 a-d$ for the Coupling Reaction of $1 \mathrm{a}, \mathrm{b}$ and $\mathbf{2 a}, \mathrm{b}$ Using $\mathrm{PdCl}_{2}$ and $\mathrm{CuCl}_{2}$ in the Absence of an Inert Atmosphere

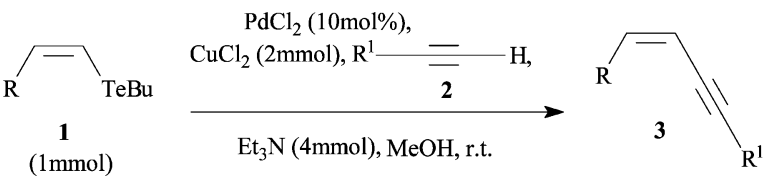

\begin{tabular}{ccccc}
\hline & \multicolumn{4}{c}{ yield (\%) $^{\mathrm{a}}$} \\
\cline { 2 - 5 } entry & $\mathbf{3 a}$ & $\mathbf{3 b}$ & $\mathbf{3 c}$ & $\mathbf{3 d}$ \\
\hline $1^{\mathrm{b}}$ & 47 & 30 & 63 & 58 \\
$2^{\mathrm{c}}$ & $68^{\mathrm{d}}$ & 40 & $82^{\mathrm{e}}$ & 79
\end{tabular}

a Isolated yield. ${ }^{b}$ Reaction performed with 1.1 equiv of the alkyne $(\mathbf{2 a}, \mathbf{b})$. Reaction time $24 \mathrm{~h}$. c Reaction performed with 2 equiv of the alkyne (2a,b). Reaction time: $48 \mathrm{~h}(\mathbf{3 a}), 48 \mathrm{~h}(\mathbf{3 b}), 36$ $\mathrm{h}$ (3c), and $40 \mathrm{~h}$ (3d). ${ }^{d}$ The homocoupling alkyne-alkyne product was obtained in a yield of $33 \%$. ${ }^{e}$ Compound $3 \mathrm{c}$ was not obtained when the reaction was carried out without $\mathrm{PdCl}_{2}$.

best results were achieved when $\mathrm{CuCl}_{2}$ was used (entries 6-8 and 10). In one case (entry 10), the reaction was carried out using the same general procedure described in Table 1, except that an inert atmosphere was not used. Good conversion was still observed. In view of this result, we performed the reaction using these new experimental conditions and using 1.1 and 2.0 equiv of the alkynes $\mathbf{2 a}$, $\mathbf{b}$ (Table 3 , eq 2 , entries 1 and 2, respectively). In this last case, improved yields were indeed observed (Table 3 , entry 2 ).

Three main features of this reaction must be emphasized. The homocoupling al kyne-alkyne compound was formed as a byproduct. No bad-smelling compound evolved during the workup, indicating that dibutyl ditelluride, a common byproduct of the transmetal ation reaction, was not obtained. Analyses of the black precipitate formed showed that the solid contained carbon and hydrogen, as indicated by microanalysis, as
Scheme 1. Proposed Mechanism for the Coupling of Vinylic Tellurides with Alkynes Catalyzed by Palladium Dichloride in the Presence of $\mathrm{CuCl}_{2}$ and Air

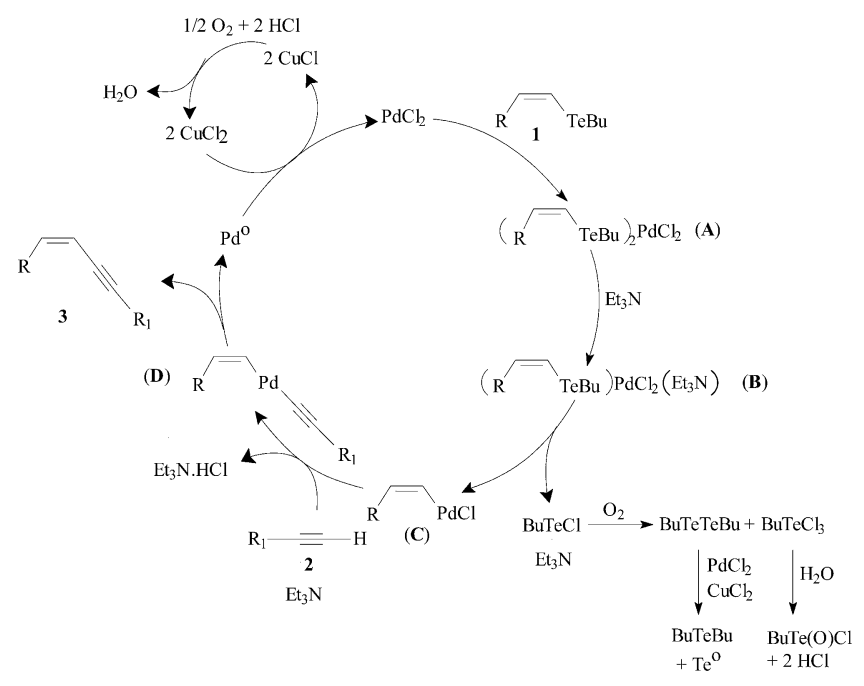

well as $\mathrm{Pd}, \mathrm{Te}$, and $\mathrm{Cu}$, as indicated by flame spectrometry analysis.

An important observation was the extraction of dibutyl telluride of the black precipitate after stirring with ethyl acetate for $48 \mathrm{~h}$. Following this observation, dibutyl ditelluride was stirred for $24 \mathrm{~h}$ under the same reaction conditions shown in Table 3 , except that no alkyne was added. In this way dibutyl telluride was obtained after addition of brine and extraction of the mixture with ethyl acetate.

A possible mechanism that accommodates the features of the coupling reaction is illustrated by the catalytic cycle of Scheme 1. This cycle was initially proposed in analogy with a published one. ${ }^{11-13}$ The palladium(II) would be recovered by oxidation of palladium(0) through a Waker process. ${ }^{27}$

Mass Spectrometric Experiments. Looking for experimental support to validate the catalytic cycle proposed in Scheme 1, we decided to investigate the coupling reaction of vinylic tellurides with alkynes promoted by $\mathrm{PdCl}_{2}$ by means of mass spectrometry techniques. Atmospheric pressure ionization (API) techniques such as el ectrospray (ESI), ${ }^{28}$ atmospheric pressure photon (APPI), ${ }^{29}$ and chemical ionization (APCI) ${ }^{30}$ gently transfer ions and neutral molecules from the reaction medium directly to the gas phase for mass spectrometric measurements. API-MS techniques are therefore useful tools to establish mechanistic pathways. ${ }^{31}$ We applied ESI to "fish" Pd- and Te-containing cationic intermediates involved in the reaction described in eq 2 directly from the reaction medium to the gas phase for ESI-MS and ESI-MS/MS analysis. Reaction of telluride $\mathbf{1 a}$ with alkyne $\mathbf{2} \mathbf{b}$ was performed according to eq 2 to give $3 c$ (Table 3 ). The reaction mixture was

(27) Tsuji, J . In Palladium Reagents and Catalysts-Innovations in Organic Synthesis; Wiley: New York, 1999.

(28) Electrospray I onization Mass Spectrometry; Cole, R. B., Ed.; Wiley: New York, 1997.

(29) (a) Robb, D. B.: Covey, T. R.; Bruins, A. P. Anal. Chem. 2000, 72, 3653. (b) Kauppila, T. J .; Kuuranne, T.; Meurer, E. C.; Eberlin, M. N.; Kotiaho, T.; Kostiainen, R. Anal. Chem. 2002, 74, 5470.

(30) Horning, E. C.; Carroll, D. I.; Dzidic, I.; Haegele, K. D.; Horning, M. D.; Stillwell, R. N. J . Chromatogr. Sci. 1974, 12, 725. 


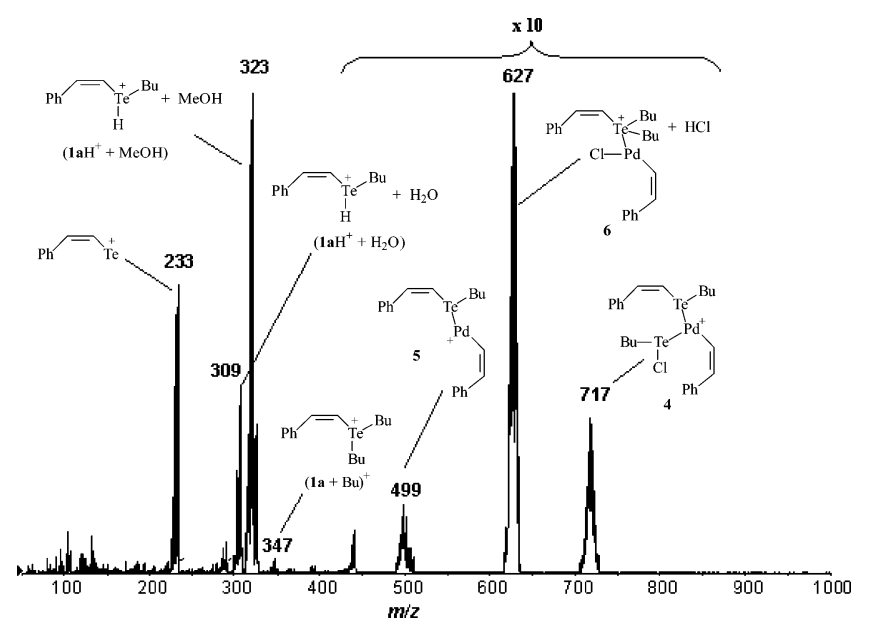

Figure 1. $\mathrm{ESI}(+)$-MS spectrum acquired after $1 \mathrm{~h}$ of reaction of $\mathbf{1 a}$ with $\mathbf{2} \mathbf{b}$, using the coupling conditions described in Table 3 (eq 2, entry 2). Note that several cationic $\mathrm{Pd}-\mathrm{Te}$ intermediates are detected.

electrosprayed via the ESI source operated in the positive ion mode, ${ }^{32}$ and the cationic species were monitored by MS analysis up to $36 \mathrm{~h}$ of reaction. After it was stirred for $1 \mathrm{~h}$, the mixture gave the ESI(+)-MS spectrum shown in Figure 1. A number of ions were detected which could be attributed to the species shown in Figure 1. The isotopic pattern of all ions matched the calculated ones for the suggested species, in particular for those containing the multi-isotope elements tellurium and palladium. The reported $\mathrm{m} / \mathrm{z}$ ratios are those of the most abundant isotopologue ions. The m/z 323 ion is likely to be the methanol adduct of the protonated starting butyl vinyl telluride $\mathbf{1 a},[\mathbf{l a H}+\mathrm{MeOH}]^{+}$. ESI $(+)-M S / M S$ shows that $[\mathbf{1 a H}+\mathrm{MeOH}]^{+}$dissociates by loss of $\mathrm{MeOH}$, giving $\mathbf{l a H}^{+}$at $\mathrm{m} / \mathrm{z} 291$, and further by butane (BuH) loss to form an ion at $\mathrm{m} / \mathrm{z} 233$ ( $\mathrm{PhCH}=$ $\mathrm{CHTe}^{+}$). The ion at $\mathrm{m} / \mathrm{z} 233$ is therefore likely derived from in-source $\mathrm{CID}$ of $[\mathbf{1 a H}+\mathrm{MeOH}]^{+}$at $\mathrm{m} / \mathrm{z} 323$, a process that we tried to minimize by sampling ions with relatively low kinetic energies, but it still occurred due
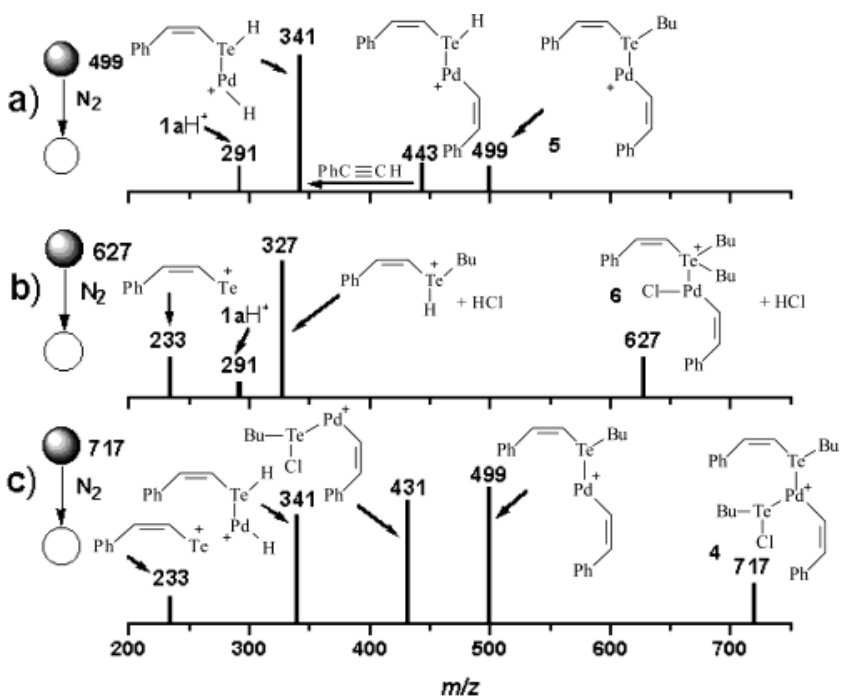

Figure 2. $\mathrm{ESI}(+)-\mathrm{MS} / \mathrm{MS}$ product ion mass spectra for low-energy (near $15 \mathrm{eV}$ ) collision-induced dissociation of the mass-selected cationic Pd- and Te-containing intermediates 5 (m/z 499), 6 (m/z 627), and 4 (m/z 717).

to the loosely bonded $[\mathbf{l a H}+\mathrm{MeOH}]^{+}$species. The ion at $\mathrm{m} / \mathrm{z} 347$ was identified as [1a $+\mathrm{Bu}]^{+}$. I ts tandem ESI $(+)-M S / M S$ spectrum showed dissociation by sequencial loss of butene and butane that yields the ion at $\mathrm{m} / \mathrm{z} 233$ $\left(\mathrm{PhCH}=\mathrm{CHTe}^{+}\right)$. These ions were also detected in a $\mathrm{ESI}$ $(+)$-MS spectrum of a solution containing solely $\mathbf{l a}$ and $\mathrm{MeOH}$. The most relevant data for the validation of the proposed catalytic cycle was the detection of three Teand Pd-containing cationic complexes; 4 at $\mathrm{m} / \mathrm{z}$ 717, 5 at $\mathrm{m} / \mathrm{z}$ 499, and $\mathbf{6}$ at $\mathrm{m} / \mathrm{z} 627$ (Figure 1). I ons 4-6 were probably formed by solution ionization of the neutral species $\mathrm{L}_{n} \mathrm{PdCl}_{2}$ : that is, $\mathrm{L}_{n} \mathrm{PdCl}_{2} \rightarrow \mathrm{L}_{n} \mathrm{PdCl}^{+}+\mathrm{Cl}^{-}$. Cations analogous to 4-6 have been suggested ${ }^{33}$ using NMR and cyclic voltammetry in reactions where $\mathrm{ArPd}^{+}$ complexes were postulated.

To structurally characterize such important cationic intermediates, ESI(+)-MS/MS experiments were performed (Figure 2). I on 5 at m/z 499 (Figure 2a) dissoci-

\section{Scheme 2. Proposed Mechanism for the Generation and Solution Equilibria of Pd-Te-Containing} Intermediates

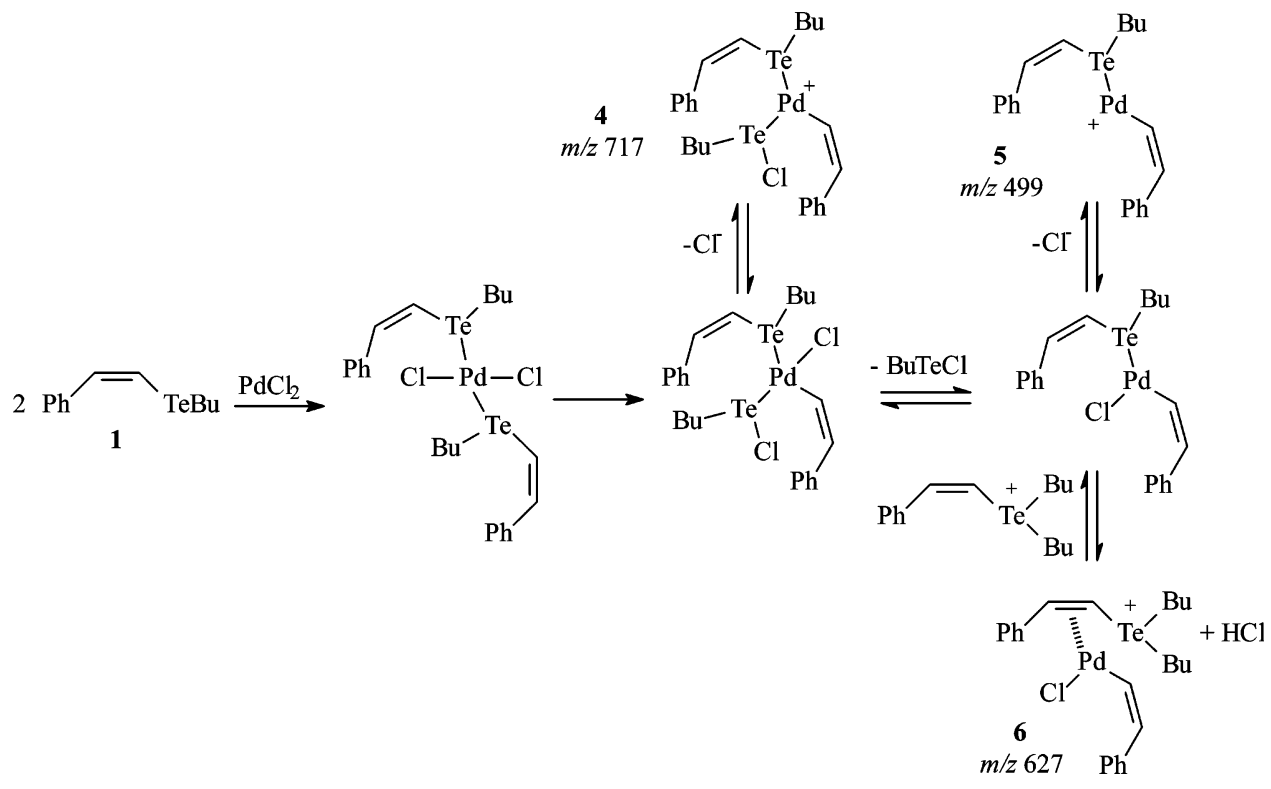




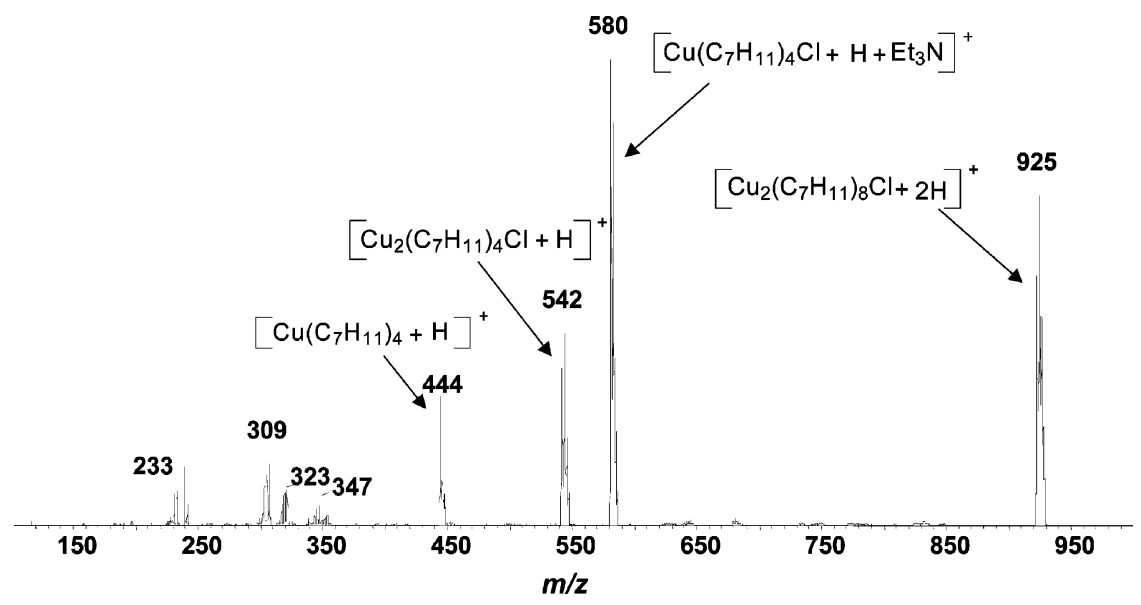

Figure 3. ESI (+)-MS mass spectrum acquired after $18 \mathrm{~h}$ of reaction of $\mathbf{1 a}$ and $\mathbf{2 b}$ using the coupling conditions described in Table 3 (eq 2, entry 2). Note that several alkynylcopper species are detected.

ated by the loss of neutral butene to yield the hydride Te complex at $\mathrm{m} / \mathrm{z} 443$ and then by loss of phenylacetylene. The intermediate 6 at $\mathrm{m} / \mathrm{z} 627$ (Figure 2b) decomposed mainly by neutral loss of $\mathrm{Cl}-\mathrm{Pd}-\mathrm{CH}=\mathrm{CHPh}$ to form an ion at $\mathrm{m} / \mathrm{z} 327$, which dissociated further by sequential loss of $\mathrm{HCl}\left(\mathbf{l a H}^{+}\right.$at $\left.\mathrm{m} / \mathrm{z} \mathbf{2 9 1}\right)$ and butane (m/z 233). I on 4 at m/z 717 (Figure 2c) showed characteristic CID pathways: loss of neutral la $(\mathrm{PhCH}=$ $\mathrm{CHTeBu}$ ) gave an ion at $\mathrm{m} / \mathrm{z} 431$. The ion at $\mathrm{m} / \mathrm{z} 499$ further dissociated to an ion at $\mathrm{m} / \mathrm{z} 341$, as seen in Figure 2a.

ESI fishing of $\mathbf{4}$ and $\mathbf{5}$ in their cationic forms suggested a solution equilibrium between these two species in the palladium insertion process, as depicted in Scheme 2 (note that $\mathbf{4}$ and $\mathbf{5}$ are shown in both their cationic $\mathrm{L}_{n} \mathrm{PdCl}^{+}$and neutral $\mathrm{L}_{n} \mathrm{PdCl}_{2}$ forms). BuTeCl acts as a ligand that stabilizes $\mathbf{4}$, which is formed by coordination of two styryl butyl tellurides to $\mathrm{PdCl}_{2}$ followed by transmetalation. Since the relative intensity of the cationic $\mathbf{4}$ and $\mathbf{5}$ remained nearly constant during up to $36 \mathrm{~h}$ of reaction, as shown by continuous ESI-MS monitoring, the ligand exchange equilibrium between $\mathbf{4}$ and $\mathbf{5}$ is likely dynamic. The mechanism in which the cationic $\mathbf{6}$ is formed is not so straightforwardly rationalized, but a possible route to $\mathbf{6}$ involves $\mathbf{5}$ in a ligand exchange process: that is, exchange of $\mathbf{1 a}$ by $[\mathbf{1 a}+\mathrm{Bu}]^{+}$

(31) (a) Feichtinger, D.; Plattner, D. A.; Chen, P. J . Am. Chem. Soc. 1998, 120, 7125. (b) Meurer, E. C.; Santos, L. S.; Pilli, R. A.; Eberlin, M. N. Org. Lett. 2003, 5, 1391. (c) Plattner, D. A. Int. J . Mass Spectrom 2001, 207, 125. (d) Kotiaho, T.; Eberlin, M. N.; Vainiotalo, P. Kostiainen, R. J . Am. Soc. Mass Spectrom. 2000, 11, 526. (e) Colton, R.; D'Agostinho, A.; Traeger, J . C. Mass Spectrom. Rev. 1995, 14, 79. (f) Cooks, R. G.; Zhang, D.; Koch, K. J .; Gozzo, F. C.; Eberlin, M. N. Anal. Chem. 2001, 73, 3646. (g) Griep-Raming, J .; Meyer, S.; Bruhn, T.; Metzger, J . O. Angew. Chem., Int. Ed. 2002, 21, 2738. (h) Sabino, A. A.; Machado, A. H. L.; Correia, C. R. D.; Eberlin, M. N. Angew. Chem., Int. Ed. 2004, 43, 2514. (i) Eberlin, M. N.; Santos, L. S.; Coelho, F. A. S. Angew. Chem., Int. Ed., in press.

(32) We also monitored the reaction with ESI-MS in the negative ion mode, but no metal anions were detected.

(33) (a) Ripa, L.; Hallberg, A. J . Org. Chem. 1996, 61, 7147. (b) Brown, J. M.; Hii, K. K. Angew. Chem., Int. Ed. Engl. 1996, 35, 657. (c) Hii, K. K.; Claridge, T. D. W.; Brown, J. M. Angew. Chem., Int. Ed. Engl. 1997, 36, 984. (d) Aliprantis, A. O.; Canary, J . W. J . Am. Chem. Soc. 1994, 116, 6985. (e) Aramendía, M. A.; Lafont, A. J . Org. Chem. 1999, 64, 3592 .

(34) (a) Wang, Z: Zhang, Z: Lu, X. Organometallics 2000, 19, 775 (b) Zhang, Z.; Lu, X.; Zang, Q.; Han, X. Organometallics 2001, 20, 3724 (c) Liu, G.; Lu, X. Tetrahedron Lett. 2002, 43, 6791. (d) de Meijere, A.; Meyer, F. E. Angew. Chem., Int. Ed. Engl. 1994, 33, 2379 and references therein.
Scheme 3. Expanded Mechanism Based on ESI (+)-MS Tandem MS/MS Experiments for the Reaction of 1 with Alkyne 2 To Give 3 Using $\mathrm{PdCl}_{2}$ and $\mathrm{CuCl}_{2}$ in the Absence of an Inert Atmosphere

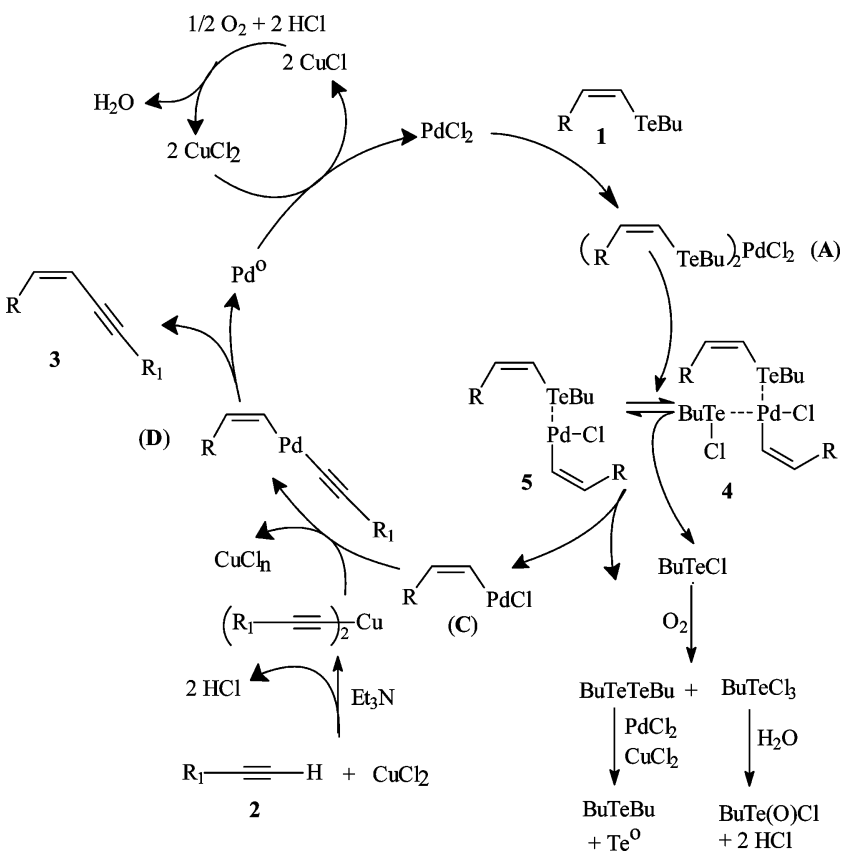

and further association with neutral $\mathrm{HCl}$ present in the reaction medium (Scheme 2). Species $\mathbf{4}$ and $\mathbf{5}$ are Pdstyryl complexes that could undergo $\beta$-hydrogen elimination to yield $\mathrm{PhC} \equiv \mathrm{CH}$. However, this acetylene was not observed as a byproduct in the coupling reaction. It is known that cations such as $\mathrm{Li}^{+}, \mathrm{Ag}^{+}$, and $\mathrm{Tl}^{+}$can inhibit such $\beta$-hydrogen eliminations. ${ }^{34}$ It is also known that cation association $(\mathbf{5} \rightarrow \mathbf{6})$ enhances the solubility of metal complexes..$^{35}$

Organocopper cluster intermediates were also identified by ESI-MS (Figure 3) and characterized as alkynylcopper species by characteristic Cu isotopic patterns and ESI-MS/MS structural analysis, and their likely compositions are shown as inserts in the spectrum of Figure 3.

On the basis of the above comments an expanded catalytic cycle (relative to that in Scheme 1) for the

(35) Alexakis, A.; Berlan, J .; Besace, Y. Tetrahedron Lett. 1986, 27, 
coupling of vinylic tellurides with alkynes catalyzed by palladium dichloride is proposed in Scheme 3.

\section{Conclusion}

The efficiency of the coupling of vinylic tellurides with al kynes catalyzed by palladium dichloride greatly depends on the amount of $\mathrm{PdCl}_{2}$ used and, most interestingly, on the presence of $\mathrm{CuCl}_{2}$, which reconverts $\mathrm{Pd}(0)$ into $\mathrm{Pd}(\mathrm{II})$. Whereas anhydrous conditions are essential, an inert atmosphere is not crucial and the reaction can be performed in the presence of air. On the basis of the unprecedented interception and structural characterization of intermediates by electrospray ionization and mass and tandem mass experiments (ESI-MS/MS), the reaction follows the catalytic cycle shown in Scheme 3, in which the reaction of $\mathbf{1}$ with alkyne $\mathbf{2}$ is used as a typical example.

\section{Experimental Section}

Materials. All reagents and solvents used were previously purified and dried, in agreement with the literature. ${ }^{38} \mathrm{THF}$ was distilled from sodium/benzophenone under $\mathrm{N}_{2}$ immediately before use. ${ }^{38} \mathrm{n}$-BuLi reagent was titrated using 1,10-phenanthroline as indicator prior to use. ${ }^{39}$ Tellurium metal (200 mesh) was obtained from Aldrich Chemical Co. and dried overnight in an oven at $100^{\circ} \mathrm{C}$. Palladium dichloride and copper (I) iodide were purchased from Aldrich Chemical $\mathrm{Co}$. and dried in a desiccator containing $\mathrm{CaCl}_{2}$ and $\mathrm{P}_{2} \mathrm{O}_{5}$ under vacuum. Chromatographic column separations were carried out with Acros Organics silica gel (230-80 mesh). $\mathrm{N}_{2}$ gas used in the reactions was deoxygenated and dried as described in the literature. 7,38 All operations were carried out in flame-dried gl assware. The following reagents were prepared according to the literature procedures: tert-butyldimethyl((1-methylprop-2-ynyl)oxy)silane $(\mathbf{7})^{40}$ and dibutyl ditelluride. ${ }^{7}$ The remaining chemicals were obtained from commercial sources. All glassware and magnetic bars used in reactions with palladium dichloride were cleaned by immersion into concentrated sulfuric acid for a few minutes and then washed with water and soap.

Instrumentation. ${ }^{1} \mathrm{H}$ and ${ }^{13} \mathrm{C}$ NMR spectra were obtained on a Bruker AC-200 $\left(200 \mathrm{MHz},{ }^{1} \mathrm{H} ; 50 \mathrm{MHz},{ }^{13} \mathrm{C}\right)$ or DRX-500 spectrometer $\left(500 \mathrm{MHz},{ }^{1} \mathrm{H} ; 125 \mathrm{MHz},{ }^{13} \mathrm{C}\right)$ or on a Varian INOVA 300 spectrometer $\left(300 \mathrm{MHz},{ }^{1} \mathrm{H} ; 75 \mathrm{MHz},{ }^{13} \mathrm{C}\right)$. All spectra were taken in $\mathrm{CDCl}_{3}$, and the chemical shifts were given in ppm with respect to tetramethylsilane (TMS) used as internal standard. ${ }^{125} \mathrm{Te}$ NMR spectra were obtained on a Bruker DRX-500 spectrometer ( $157 \mathrm{M} \mathrm{Hz}$, ${ }^{125}{ }^{\mathrm{Te}}$ ) using $\mathrm{CDCl}_{3}$ as solvent. The chemical shifts were referenced to diphenyl ditelluride, $(\mathrm{PhTe})_{2}$, in $\mathrm{CDCl}_{3}\left(1 \mathrm{~mol} \mathrm{~L}^{-1}\right)(\delta 420 \mathrm{ppm}$ at 25 ${ }^{\circ} \mathrm{C}$ ) as external standard. Low-resolution mass spectra were obtained on a Shimadzu CG-17A/CGMS-QP5050A instrument. ESI-MS ${ }^{n}$ analyses were performed on a Q-Trap Applied Biosystem MDS spectrometer. The tandem mass spectrometric (MS/MS) experiments were performed using ESI and Q1 mass selection of the desirable product ion, q2 collision-induced dissociation (CID) with $\mathrm{N}_{2}$, and linear ion-trap mass analysis of the $\mathrm{CID}$ ionic fragments. The collision energy ranged from

(36) Sonogashira, K.; Tohda, Y.; Hagihara, N. Tetrahedron Lett. 1975, 4467

(37) (a) Rossi, R.; Carpita, A.; Belina, F. Org. Proc. Int. 1995, 27, 129. (b) Campbell, I. B. In Organocopper Reagents; Taylor, R. J . K., Ed.; IRL Press: Oxford, U.K., 1994; pp 217-235. (c) Frosch, W.; Back, S.; Kohler, K.; Lang, H. J . Organomet. Chem. 2000, 601, 226.

(38) Perrin, D. D.; Armarego, W. L. F. In Purification of Laboratory Chemicals; Pergamon Press: Oxford, U.K., 1980.

(39) Watson, S. C.; Eastham, J . F. J . Organomet. Chem. 1967, 9, 165 6190.
5 to $15 \mathrm{eV}$, depending on the dissociation liability of the precursor ion. The reaction was performed as described and analyzed by spraying aliquots of the reaction mixture through the ESI source. As the postulated intermediates in mechanisms (Scheme 1) could have basic sites (tel lurium) or cationic intermediates, we selected the positive mode of ion detection. Near-IR spectra were obtained on a Bomem MB-100 spectrometer. Elemental analyses were performed at the $\mathrm{Mi}$ croanalytical Laboratory of the Institute of Chemistry, Universidade de São Paulo. Tellurium, palladium, and copper were analyzed on a Spectro spectroflame in the same laboratory of the Institute of Chemistry, Universidade de São Paulo. The IUPAC names were obtained using the software ISIS/Draw, version 2.4

General Procedure. Preparation of the Vinylic Tellurides. ${ }^{7}$ To a solution of the dibutyl ditelluride (5.54 g, 15 $\mathrm{mmol})$ and the appropriate acetylene $(\mathbf{2 a}, \mathbf{7})(30 \mathrm{mmol})$ in absolute ethanol (150 mL) under deoxygenated and dry nitrogen and magnetic stirring was added $\mathrm{NaBH}_{4}(1.6 \mathrm{~g}, 42$ $\mathrm{mmol}$ ) in small portions until the solution turned from dark red to paleyellow. The mixture was then refluxed for $4 \mathrm{~h}$. After that, the solvent was evaporated under reduced pressure. To the residue was added $100 \mathrm{~mL}$ of brine, and the organic material was extracted with ethyl acetate $(3 \times 100 \mathrm{~mL})$. The combined organic phases were dried with magnesium sulfate and filtered. The organic solvent was evaporated under reduced pressure, and the residue was purified by column chromatography on silica gel with hexane as eluent.

(2-Butyltellanyl-(Z)-vinyl)benzene (1a). Yield: $6.99 \mathrm{~g}$ (81\%). The spectral data agreed with those from the literature. ${ }^{7}$

tert-Butyl((3-(butyltellanyl)-1-methyl-(Z)-allyl)oxy)dimethylsilane (1b). Yield: $5.55 \mathrm{~g}(50 \%) .500 \mathrm{MHz}{ }^{1} \mathrm{H}$ NMR $\left(\mathrm{CDCl}_{3} ; \mathrm{ppm}\right): 6.55(\mathrm{~d}, \mathrm{~J}=9.7 \mathrm{~Hz}, 1 \mathrm{H}), 6.23(\mathrm{dd}, J=9.7 \mathrm{~Hz}$, $7.1 \mathrm{~Hz}, 1 \mathrm{H}$ ), 4.30 (quint $_{\mathrm{ap}} \mathrm{J}=6.3 \mathrm{~Hz}, 1 \mathrm{H}$ ), $2.69-2.59(\mathrm{~m}, 2 \mathrm{H}$ ), 1.76 (quint, J $=7.5 \mathrm{~Hz}, 2 \mathrm{H}$ ), 1.39 (sext, J $=7.4 \mathrm{~Hz}, 2 \mathrm{H}$ ), 1.18 $(\mathrm{d}, \mathrm{J}=6.3 \mathrm{~Hz}, 3 \mathrm{H}), 0.92(\mathrm{t}, \mathrm{J}=7.4 \mathrm{~Hz}, 3 \mathrm{H}), 0.89(\mathrm{~s}, 9 \mathrm{H}), 0.08$

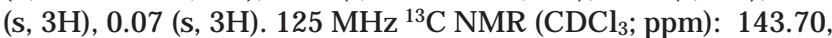
100.30, 71.97, 34.11, 25.98, 24.93, 23.42, 18.23, 13.40, 6.98, -4.34, -4.67. $157 \mathrm{MHz}{ }^{125} \mathrm{Te} \mathrm{NMR}\left(\mathrm{CDCl}_{3} ; \mathrm{ppm}\right): 264.89$. LRMS (m/z (relative intensity)): $372\left(\mathrm{M}^{+}, 6.7 \%\right), 370\left(\mathrm{M}^{+}-\right.$ 2, 6.2\%), $368\left(\mathrm{M}^{+}-4,3.8 \%\right), 315(12.0 \%), 313(11.3 \%), 311$ (6.9\%), 241 (8.1\%), 239 (6.0\%), 237 (4.4\%), 185 (17.6\%), 127 (100.0\%), 73 (78.3\%). near-IR (film; cm-1): 2958 (s), 2929 (s), $2857(\mathrm{~s}), 1598(\mathrm{w}), 1466(\mathrm{~m}), 1366(\mathrm{~m}), 1253(\mathrm{~s}), 1092(\mathrm{~s}), 834$ (s). Anal. Calcd for $\mathrm{C}_{14} \mathrm{H}_{30} \mathrm{OSiTe}$ C, 45.44; $\mathrm{H}, 8.17$. Found: C, 45.38; H, 8.05.

Preparation of Compounds $3 \mathrm{a}-\mathrm{d}$ using $\mathrm{PdCl}_{2}$ and $\mathrm{Cul}$ (See Table 1). A $25 \mathrm{~mL}$ two-necked round-bottomed flask was flame-dried under a flow of deoxygenated and dry nitrogen. $\mathrm{PdCl}_{2}$ was added and was flame-dried under a flow of the same gas. Then, Cul was added and the drying procedure was repeated. Afterward, under an inert atmosphere, dry methanol and then the appropriate vinylic tel luride $(\mathbf{l a}, \mathbf{b})$ were added. An orange mixture was obtained and was stirred for $15 \mathrm{~min}$ at room temperature. After that, the appropriate freshly distilled terminal alkyne (2a,b) and dry triethylamine were added. The addition of dry triethylamine turned the mixture from orange to black. The reaction mixture was stirred under an inert atmosphere at room temperature for the time indicated in Table 1. Then, the solids were filtered off over Celite and washed many times with methanol. The solvent was evaporated under reduced pressure. To the residue was added brine $(50 \mathrm{~mL})$, and the mixture was extracted with ethyl acetate $(3 \times 50 \mathrm{~mL})$. The combined organic phases were dried with magnesium sulfate and then filtered. The conversions were determined by GC (entries 1-5, Table 1 ). For entry 5 in Table 1, the organic solvent was evaporated under reduced pressure and the residue was purified by column chromatography on silica gel using hexane or pentane as eluent.

(Z)-tert-Butyldimethyl((1-methyldec-2-en-4-ynyl)oxy)silane (3a). Eluent: hexane. Yield: $0.249 \mathrm{~g}$ (89\%). $500 \mathrm{MHz}$ 
$\left.{ }^{1} \mathrm{H} \mathrm{NMR} \mathrm{(CDCl} 3 ; \mathrm{ppm}\right): 5.79$ (dd, J $\left.=10.8 \mathrm{~Hz}, 8.3 \mathrm{~Hz}, 1 \mathrm{H}\right)$, 5.36 (dtd, J $=10.8,2.2,1.0 \mathrm{~Hz}, 1 \mathrm{H}$ ), 4.81 (dqd, J = 8.3, 6.3, $1.0 \mathrm{~Hz}, 1 \mathrm{H}), 2.33(\mathrm{td}, \mathrm{J}=7.0,2.2 \mathrm{~Hz}, 2 \mathrm{H}), 1.54$ (quint, $\mathrm{J}=7.1$ $\mathrm{Hz}, 2 \mathrm{H}), 1.43-1.30(\mathrm{~m}, 4 \mathrm{H}), 1.22(\mathrm{~d}, \mathrm{~J}=6.3 \mathrm{~Hz}, 3 \mathrm{H}), 0.91(\mathrm{t}$, $\mathrm{J}=7.2 \mathrm{~Hz}, 3 \mathrm{H}), 0.89(\mathrm{~s}, 9 \mathrm{H}), 0.08(\mathrm{~s}, 3 \mathrm{H}), 0.06(\mathrm{~s}, 3 \mathrm{H}) .125$ $\mathrm{MHz}{ }^{13} \mathrm{C} \mathrm{NMR}\left(\mathrm{CDCl}_{3} ; \mathrm{ppm}\right): 146.36,107.74,95.58,76.65$, 67.18, 31.08, 28.49, 25.92, 23.85, 22.23, 19.46, 18.22, 13.99, -4.54, -4.85. Near-IR (film; cm-1): 3025 (w), 2958 (s), 2932 (s), $2898(\mathrm{~m}), 2861(\mathrm{~s}), 2216(\mathrm{w}), 1616(\mathrm{w}), 1465(\mathrm{~m}), 1366(\mathrm{w})$, $1253(\mathrm{~m}), 1071(\mathrm{~s}), 996(\mathrm{~m}), 837$ (s). LRMS (m/z (relative intensity)): 265 (0.6\%), 223 (5.2\%), 147 (19.0\%), 75 (100.0\%). Anal. Calcd for $\mathrm{C}_{17} \mathrm{H}_{32} \mathrm{OSi}$ : C, 72.79; $\mathrm{H}, 11.50$. Found: $\mathrm{C}, 73.09$; $\mathrm{H}, 11.42$.

(Z)-tert-B utyldimethyl((1-methyl-5-phenylpent-2-en-4ynyl)oxy)silane (3b). Eluent: hexane. Yield: $0.263 \mathrm{~g}$ (92\%). $500 \mathrm{MHz}^{1} \mathrm{H}$ NMR (CDCl $\left.3 ; \mathrm{ppm}\right): 7.43-7.41$ (m, 2H), 7.33$7.31(\mathrm{~m}, 3 \mathrm{H}), 5.94(\mathrm{dd}, \mathrm{J}=10.8,8.4 \mathrm{~Hz}, 1 \mathrm{H}), 5.61(\mathrm{dd}, \mathrm{J}=$ $10.8,0.7 \mathrm{~Hz}, 1 \mathrm{H}$ ), 4.91 (quint $_{a p} \mathrm{~d}, \mathrm{~J}=7.3,0.7 \mathrm{~Hz}, 1 \mathrm{H}$ ), $1.28(\mathrm{~d}$, $\mathrm{J}=6.3 \mathrm{~Hz}, 3 \mathrm{H}), 0.90(\mathrm{~s}, 9 \mathrm{H}), 0.11(\mathrm{~s}, 3 \mathrm{H}), 0.08(\mathrm{~s}, 3 \mathrm{H}) .125$ $\mathrm{MHz}{ }^{13} \mathrm{C} \mathrm{NMR}\left(\mathrm{CDCl}_{3}\right.$; ppm): 147.71, 131.35, 128.34, 128.21, $123.38,107.26,94.27,85.49,67.25,25.90,23.87,18.21,-4.49$ -4.80. Near-IR (film; cm ${ }^{-1}$ ): 3060 (w), 3027 (w), 2956 (m), 2931 (m), $2890(w), 2857(m), 2199(w), 1597(w), 1490(w), 1467$ (w), 1443 (w), 1397 (w), 1365 (w), 1254 (m), 1080 (s), 836 (s), 777 (s), 754 (s). LRMS (m/z (relative intensity)): $286\left(\mathrm{M}^{+}\right.$, 0.1\%), 229 (54.4\%), 155 (29.8\%), 75 (100.0\%). Anal. Calcd for $\mathrm{C}_{18} \mathrm{H}_{26} \mathrm{OSi}: \mathrm{C}, 75.46 ; \mathrm{H}, 9.15$. Found: $\mathrm{C}, 75.58 ; \mathrm{H}, 9.10$.

((Z)-Non-1-en-3-ynyl)benzene (3c). Eluent: pentane. Yield: $0.184 \mathrm{~g}(93 \%)$. The spectral data agreed with those from the literature. ${ }^{14}$

(Z)-1,4-Diphenylbut-1-en-3-yne (3d). Eluent: hexane. Yield: $0.190 \mathrm{~g}$ (93\%). The spectral data agreed with those from the literature. ${ }^{41}$

Preparation of Compounds $3 a-d$ using $\mathbf{P d C l}_{2}$ in the Absence of Cul (See Table 1). The reactions were performed in the absence of Cul, as indicated in Table 1 using the procedure described above. The conversions were determined by GC (entries 6-8, Table 1). Compound 3c (entry 8, Table 1) was extracted and purified as described above. Yield: $0.149 \mathrm{~g}$ (75\%).

Preparation of Compound $3 c$ using a Catalytic Amount of $\mathrm{PdCl}_{2}$ and Several Oxidizing Agents or Additives (See Table 2). The reactions were performed in the presence of oxidizing agents or additives, as indicated in Table 2, using the procedure described above. The conversions were determined by GC (entries 1-10, Table 2). Compound 3c (entry 10, Table 2) was extracted and purified as described above. Yield: $0.125 \mathrm{~g}$ (63\%).

Preparation of Compound $3 \mathrm{C}$ using $\mathrm{PdCl}_{2}$ and $\mathrm{Cul}$ in the Absence of an Inert Atmosphere and without Previous Stirring for $\mathbf{1 5} \mathbf{~ m i n}$. The reaction (entry 5, Table 1, compound $\mathbf{3 c}$ ) was performed in the absence of an inert atmosphere. The terminal alkyne $\mathbf{2} \mathbf{a}$ and dry triethylamine

(41) Galli, C.; Gentili, P.; Rappoport, Z. J . Org. Chem. 1994, 59, 6786. were added to the reaction mixture immediately after the addition of the vinylic telluride $\mathbf{1 a}$. Compound $\mathbf{3 c}$ was extracted and purified. Yield: $0.188 \mathrm{~g}$ (95\%). The conversion, determined by GC, was $>99 \%$.

Preparation of Compounds $3 a-d$ using $\mathrm{PdCl}_{2}$ and $\mathrm{CuCl}_{2}$ in the Absence of an Inert Atmosphere (See E ntry 1, Table 3). A $25 \mathrm{~mL}$ two-necked round-bottomed flask was flame-dried with magnetic stirring and under a flow of deoxygenated and dry nitrogen. $\mathrm{CuCl}_{2}(0.269 \mathrm{~g}, 2 \mathrm{mmol})$ was added and was flame-dried under a flow of the same gas until it became brown. Then, $\mathrm{PdCl}_{2}(0.018 \mathrm{~g}, 0,1 \mathrm{mmol})$ was added and the drying procedure was repeated. Afterward, in the absence of an inert atmosphere, dry methanol $(10 \mathrm{~mL})$ was added. A green mixture was obtained. Then, the appropriate vinylic telluride $(\mathbf{1 a}, \mathbf{b} ; \mathbf{1} \mathbf{m m o l})$ was added. The addition of the vinylic telluride $(\mathbf{l} \mathbf{a}, \mathbf{b})$ turned the mixture from green to brown. After that, the appropriate freshly distilled terminal alkyne (2a,b; $1.1 \mathrm{mmol})$ and dry triethylamine $(0.404 \mathrm{~g}, 0.6$ $\mathrm{mL}, 4 \mathrm{mmol}$ ) were added. The addition of dry triethylamine turned the mixture from brown to black. The reaction mixture was stirred in the absence of an inert atmosphere under anhydrous conditions at room temperature for $24 \mathrm{~h}$. Then, the solids were filtered off over Celite, being washed many times with methanol. The solvent was evaporated under reduced pressure. To the residue was added brine $(50 \mathrm{~mL})$, and it was extracted with ethyl acetate $(3 \times 50 \mathrm{~mL})$. The combined organic phases were dried with magnesium sulfate and then filtered. The organic solvent was evaporated under reduced pressure, and the residue was purified by column chromatography on silica gel using the appropriate eluent. 3a: eluent hexane; yield $0.132 \mathrm{~g}$ (47\%). 3b: eluent hexane; yield $0.086 \mathrm{~g}$ (30\%). 3c: eluent pentane; yield: $0.125 \mathrm{~g} \mathrm{(63 \% ).} \mathrm{3d:} \mathrm{eluent}$ hexane; yield $0.118 \mathrm{~g}(58 \%)$.

Preparation of Compounds $3 a-d$ using $\mathrm{PdCl}_{2}$ and $\mathrm{CuCl}_{2}$ in the Absence of an Inert Atmosphere (See E ntry $\mathbf{2}$, Table 3). The reactions were performed using $2 \mathrm{mmol}$ of the appropriate terminal alkyne $(\mathbf{2} \mathbf{a}, \mathbf{b})$, as indicated in Table 3 using the last procedure described above. The compounds (entry 2, Table 3) were extracted and purified: 3a: reaction time $48 \mathrm{~h}$; eluent hexane; yield $0.190 \mathrm{~g}(68 \%)$. 3b: reaction time $48 \mathrm{~h}$; eluent hexane; yield $0.114 \mathrm{~g}(40 \%) .3 \mathrm{c}$ : reaction time $36 \mathrm{~h}$; eluent pentane; yield $0.163 \mathrm{~g}(82 \%) .3 \mathrm{~d}$ : reaction time $40 \mathrm{~h}$; el uent hexane; yield $0.161 \mathrm{~g}(79 \%)$.

Acknowledgment. We acknowledge the following Brazilian foundations for financial support: Brazilian National Science Council (CNPq), Instituto do Milênio de Materiais complexos (FINEP-MST), and São Paulo State Science Foundation (FAPESP). The DAAD is acknowledged for an undergraduate fellowship to M.H.G.P. from the University of Wuppertal, Wuppertal, Germany. J .V.C. thanks Prof. Liliana Marzorati for the critical revision of the paper.

OM049805W 